SIR,-Dr A H Choudhri and colleagues unfortunately give no details of the radiographic projections used to image the renal arteries. ${ }^{1}$ I would seem likely that the renal arteries were imaged only in a single anteroposterior projection.

Anatomically the renal arteries arise from the anterior quadrants of the aorta, with the right renal artery usually arising more anteriorly than the left. ${ }^{2}$ A single conventional anteroposterior projection done in conjunction with an aortic flush will provide inadequate visualisation of the origins of the renal artery, particularly on the right. The recommended projection is the $25^{\circ}$ right posterior oblique, which throws both renal arteries, and particularly their origins, into profile. ${ }^{3}$

It has been our experience of renal artery imaging using digital subtraction angiography that without the use of this oblique projection stenoses may be missed, resulting in the underreporting of proximal lesions.

T M BUCKENHAM C D GEORGE

Department of Diagnostic Radiology, St George's Hospital, London SW17 0QT

1 Choudhri AH, Cleland JGF, Rowlands PC, Tran TL, McCarty $\mathrm{M}$, Al-Kutoubi MAO. Unsuspected renal artery stenosis in peripheral vascular disease. BMF 1990;301:1197-8. (24 November.)

2 Odman P, Ranniger $\mathrm{K}$. The location of the renal arteries: angiographic and postmortem study. Am $\mathcal{F}$ Roentgenol 1968;104:283-8.

Johnsrude IS, Jackson DC. A practical approach to angiography. Boston: Little, Brown, 1979:122.

AUTHORS' REPLY,-Dr Donovan suggests that serum creatinine concentration is a poor index of glomerular filtration but suggests no better alternative. Measurement of serum creatinine is the most widely used index of glomerular function, is simple, is relatively resistant to major technica artefacts, and is probably at least as good as measuring creatinine clearance using 24 hour urine collections and simultaneous blood sampling. Cockcroft and Gault showed that the difference between creatinine clearance estimated from the serum creatinine concentration was no greater than that between paired measurements of creatinine clearance. ${ }^{2}$ Morgan et al recommended that the measurement of creatinine clearance should be abandoned in favour of measurement of serum creatinine alone over 10 years ago. ${ }^{3}$ Moreover, many patients are poorly instructed in how to perform a urine collection and others are just poorly motivated, making creatinine clearance an even more unreliable estimate of glomerular filtration. Measurement of serum creatinine circumvents this source of error. Inulin clearance or measurements of glomerular filtration using radioisotopes may well be more accurate measures of renal function, but these are not in widespread clinical use. Thus serum creatinine concentration is probably the best method in widespread clinical use for the estimation of global renal function.

The purpose of our paper was not to identify specific patients at high risk of renal dysfunction during inhibition of angiotensin converting enzyme but rather to alert the practitioner to a group of patients that contains individuals at high risk who should be assessed in greater detail. Serum creatinine concentration, which we believe to be the best practicable way of assessing glomerular filtration in a large number of subjects in a busy clinical practice, may be normal even in the presence of significant bilateral renal artery stenosis. Thus, a normal serum creatinine concentration should not lull the clinician into a false sense of security.

Drs Buckenham and George query renal artery imaging. A single anteroposterior projection was usually obtained as an adjunct to the main procedure, which was of course assessment of the peripheral circulation. If the renal arteries were obscured by other vessels oblique views were obtained. We agree that the single anteroposterior projection tends to underestimate the incidence of renal artery stenosis, but in our experience and that of others ${ }^{4}$ no single projection is likely to be entirely satisfactory if imagining the renal arteries is part of an aortic injection. Although a right posterior oblique projection may be more likely to show the origins of both renal arteries than an anteroposterior projection, an anteroposterior projection is an acceptable alternative as a useful guide to renal anatomy and for assessing the main renal arteries.

We routinely use the anteroposterior projection and both oblique projections when formally examining the renal arteries with an aortic injection. Even so it is sometimes necessary to catheterise the renal artery selectively to obtain unequivoca information. In this group of patients the renal arteries were examined as part of a research project in patients with no known renal artery disease, so it was not thought appropriate to increase risk due to catheter manipulation or exposure to radiation and contrast beyond the minimum.

Now that we have shown that there is a significant incidence of renal artery stenosis in this group of patients we think that the procedure could be extended for adequately evaluating the renal arteries. The thrust of our work was to highlight the incidence of renal artery stenosis in these patients; a slight underestimation of the incidence should only underline this point.

In reply to Dr D Kerr and Professor $\mathrm{R}$ Tattersall we would like to point out that the first patient had glomerular filtration measured one month after stopping an angiotensin converting enzyme inhibitor. In the second patient renal function did not improve after the angiotensin converting enzyme inhibitor was stopped. We have shown that plasma concentrations of angiotensin II and glomerular filtration would be expected to return to normal within a few days of the angiotensin converting enzyme inhibitor being stopped.

Although measurement of glomerular filtration by radioisotopes may be more sensitive to changes in glomerular filtration, the technique is affected by technical artefacts that render changes in an individual patient difficult to interpret. Extravasation of isotope from the vein and inadvertent timing of blood sampling may have important effects on the result. These problems are less important when groups of patients are studied because they are randomly distributed and merely increase the "noise" within the study. The changes in glomerular filtration rate reported above are similar to those seen in heart failure in patients without stigmata (including peripheral vascular disease) of renal artery stenosis ${ }^{7-9}$ and are consisten with the expected effects of angiotensin II suppression on the kidney.

No major change in serum creatinine concentration occurred and neither patient required dialysis. Although the findings are interesting, they may not be clinically relevant.

A H CHOUDHRI J G F CLELAND P C ROWLANDS T L TRAN M MCCARTY St Mary's Hospital M A O AL-KUTOUBI

London W2 INY

Wibell L, Biorsell-Ostling E. Endogenous creatinine clearance in apparently healthy individuals as determined by 24-hour ambulatory urine collection. Uppsala f Med Sci 1973;78:43-56. from serum creatinine. Nephron 1975;16:31.

Morgan DB, Dillon S, Payne RB. The assessment of glomerula function: creatinine clearance or plasma creatinine? Postgrad Med f 1978;54:302-10.

+ Johnsrude IS, Jackson DC, Dunnick NR. A practical approach to angiography. 2nd ed. Boston: Little, Brown, 1987:259-63.

5 Kerr D, Tattersall R. Renal artery stenosis. BMF 1991;302:115. (12 January.)

6 Cleland JG, Dargie $\mathrm{HJ}$. Heart failure, renal function and
S220-8

Cleland JGF, Dargic HJ, Hodsma

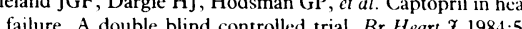
$530-5$

8 Cleland JGF, Dargie HJ, Ball SG, et al. Effects of enalapril in heart failure: a double blind study of effects on exercise performance, renal function, hormones, and metabolic state. Br Heart f 1985:54:305-12.

9 Cleland JGF, Gillen G, Dargie HJ. The effects of frusemide and angiotensin-converting enzyme inhibitors and their combination on cardiac and renal haemodynamics in heart failure. Eur Heart f 1988;9:132-41.

\section{Bleeding tonsils}

SIR, - Mr Mark G Watson recently drew attention to the problem of spontaneous tonsillar haemorrhage. ${ }^{1}$ We report a further cause of this condition.

A previously fit 20 year old man presented having been spitting blood for two days. His history was unremarkable, but examination showed a bleeding point on the lower left faucial tonsil. He had a blood pressure of $240 / 140 \mathrm{~mm} \mathrm{Hg}$ in both arms with no radiofemoral delay; a displaced heaving apex beat; and severe arteriolar narrowing and twisting in his fundi. Chest radiography showed cardiomegaly, and left ventricular hypertrophy and strain were evident on electrocardiography. Full blood count, clotting studies, biochemical profile, and urine analysis all gave normal results. Within two hours after the start of intravenous sodium nitroprusside the bleeding had stopped, and within 12 hours his blood pressure was $160 / 90 \mathrm{~mm} \mathrm{Hg}$. Further investigations failed to identify any underlying cause for his hypertension and he was discharged four days later. He continued to take atenolol and slow release nifedipine and his blood pressure remained normal; he has had no further tonsillar haemorrhages.

Haemorrhage is a recognised presentation of severe hypertension; cerebrovascular accidents are common, the severity of epistaxes is thought to be related to blood pressure, ${ }^{2}$ and frank haematuria and haematospermia have been reported. ${ }^{3}$ Our case shows that severe hypertension can also present as spontaneous tonsillar haemorrhage.

G E MURTY N J SAMANI J R MOLONEY

Leicester Royal Infirmary,

Leicester LE1 5WW

I Watson MG. Bleeding tonsils. BMF 1990;301:1233-4. (1 December.)

2 Shaheen OH. Arterial epistasis. F Laryngol Otol 1975;89:17-34

Swales JD. Clinical hypertension. London: Chapman and Hall, 1979:137-8.

\section{Hospital admissions for accidents in preschool children}

SIR,-In Solihull District Health Authority we examined our hospital inpatient data to see if admissions of children for accidents had any epidemiological patterns. We used data from the regional information system for all Solihull residents during the year April 1989 to March 1990. I excluded admissions for birth (ICD 9 codes V300 and V290) when calculating admission rates and defined admissions as finished consultant episodes. (This analysis could not have been done without the diligent data entry by the unsung hero(ine)s of NHS statistics: the coding clerks.)

The distribution of ages of children admitted in relation to accidents formed a shallow $U$ shape. Boys were admitted more often than girls in all age groups, and the rise in both teenage and preschool accidents was predominantly among boys.

When considering rates of diagnosis by total population it is important to realise that small numbers may affect any comparison. Nevertheless, 